\title{
Sanción moratoria por consignación inoportuna de cesantías a servidores públicos: jurisdicción competente y derechos fundamentales $^{*}$
}

Moratorium indemnification by the late payment of the severance pay (cesantias) to public servants: jurisdiction and fundamental rights

Fecha de recepción: 12 de octubre de 2018

Fecha de aprobación: 18 de enero de 2019

\section{Resumen}

Ha sido una constante la incertidumbre en la jurisdicción competente para tramitar y decidir los procesos que versan sobre el pago de la indemnización moratoria por consignación tardía de cesantías a servidores públicos. Partiendo de un estudio conciso sobre el alcance de las tesis jurisprudenciales edificadas al respecto, y paralelamente, de sus ambigüedades, matices y efectos en los procesos instruidos por despachos laborales y contencioso administrativos de nuestro país, el autor asevera y explica por qué la ausencia de uniformidad y coherencia en cuanto a la vía procesal de solución de estas controversias constituye una trasgresión a los derechos constitucionales fundamentales al debido proceso, la igualdad, el acceso a la administración de justicia y los principios de confianza legítima y seguridad jurídica. En

* El presente artículo es producto del proyecto de investigación: "Sanción moratoria por consignación inoportuna de cesantías a servidores públicos: jurisdicción competente y derechos fundamentales”, desarrollado en el marco del programa de la Especialización en Derecho Administrativo de la Universidad Santo Tomás, Bogotá. Citar como Figueroa Salamanca, O. (2019). Sanción moratoria por consignación inoportuna de cesantías a servidores públicos: jurisdicción competente y derechos fundamentales. Via Inveniendi et Iudicandi, 14(2), 145-174. DOI: https://doi.org/10.15332/19090528.5042

** Abogado de la Pontificia Universidad Javeriana. Especialista en Derecho Administrativo. Consultor y litigante. Bogotá, Colombia. Correo electrónico: oscarlfs@hotmail.com. Orcid: https://orcid.org/0000-0002-1801-625X 
la parte final se enaltece la reciente adopción de un criterio más o menos unívoco como garantía de verdadero respeto al precedente judicial, aunque se llama a la prudencia frente a la aplicación sorpresiva de cambios jurisprudenciales a procesos ejecutivos en curso.

Palabras clave: sanción moratoria, cesantías, conflictos de jurisdicción, igualdad, precedente judicial, seguridad jurídica.

\section{Abstract}

It has been a constant the uncertainty in the jurisdiction that processes and decides lawsuits about the moratorium indemnification by the late payment of the severance pay (cesantías) to public servants. Beginning from a concise study about the scope of the jurisprudential thesis built around the previous statement, and its ambiguities, nuances and effects in the labor courts and contentious-administrative courts of our country, the author asserts and explains how the lack of uniformity and coherence about the proceeding for the solution of these controversies, constitutes a transgression against fundamental constitutional rights, mainly the due process, equality, access to the administration of justice and the principles of legitimate expectations and legal certainty. At the end, this work exalts the recent adoption of a more or less uniform criterion as a guarantee of true respect for the judicial precedent, nevertheless, it is necessary to be prudent about the surprising application of jurisprudential changes to ongoing executive proceedings.

Keywords: Moratorium indemnification, severance pay, conflicts of jurisdiction, equality, judicial precedent, legal certainty. 


\section{INTRODUCCIÓN}

El consabido proceder tardío de la administración pública en la cancelación del auxilio de cesantía a sus servidores, como si el excepcional incumplimiento obligacional fuese moldeando - con resignación — una conducta estatal reiterativa y predecible, ha generado una creciente interposición de demandas encaminadas al resarcimiento del daño así irrogado, tanto por la vía del proceso ejecutivo laboral como del medio de control de nulidad y restablecimiento del derecho.

El presente escrito tiene por objetivo analizar las posiciones que han surgido a propósito de la jurisdicción llamada a resolver las controversias referentes al pago de la sanción moratoria por la cancelación tardía de las cesantías establecida en las leyes 244 de 1995 y 1071 de 2006. Desde una perspectiva crítica, dada la reciente emisión de una providencia que pretende zanjar el debate, se pretende reafirmar la necesidad de adoptar reglas uniformes pues bastantes son las ocasiones en que los servidores públicos han visto frustrada su aspiración indemnizatoria por causa de tesis antagónicas sentadas por juzgados laborales y contencioso administrativos, tanto más si aquella ausencia de univocidad ha podido derivarse de pronunciamientos discordantes del Consejo de Estado y la Sala Jurisdiccional Disciplinaria del Consejo Superior de la Judicatura como órganos de cierre.

En ese contexto, el problema de investigación atańe al alcance e impacto que tiene la determinación de la vía procesal de reclamación de dicha sanción en los derechos a la igualdad y tutela judicial efectiva de los servidores afectados por la tardanza del Estado en el pago de sus cesantías parciales o definitivas.

La justificación de las siguientes líneas no se agota en un breviario sobre la aludida sanción y los elementos que aportan a la fijación del juez competente, aunque bien servirá a litigantes, operadores judiciales y comunidad con interés en la temática. Se trata sobre todo de una aproximación al camino adecuado para obtener su recaudo bajo el marco del derecho fundamental de acceso a la administración de justicia, el respeto del precedente y el axioma de seguridad jurídica. 
Finalmente, el método empleado es el analítico, que hace uso de la hermenéutica seguida por las altas corporaciones judiciales, examinada a partir de fuentes primarias o importantes referentes teóricos en derecho procesal, administrativo y constitucional, con particular énfasis en la teoría de los derechos primarios.

Inspirado el legislador en la necesidad de poner fin al constante menoscabo por parte de las entidades públicas encargadas del reconocimiento del auxilio de cesantías a sus trabajadores, al paso de proscribir favorecimientos indebidos y la malsana corrupción $^{1}$, mediante los arts. 1 y 2 de la Ley 244 de 1995 señaló un término perentorio para que la administración expidiera la resolución de reconocimiento de tal prestación social y la cancelara en forma tempestiva.

Conservando la misma lógica, los arts. 4 y 5 de la Ley 1071 de 2006 -que subrogaron los precitados cánones- establecen plazos de: i) 15 días hábiles después de radicada la solicitud para que "la entidad empleadora o aquella que tenga a su cargo el reconocimiento y pago de las cesantías" parciales o definitivas expida el acto administrativo de otorgamiento, si el interesado reúne enteramente los requisitos; y ii) 45 días hábiles para proceder al pago contados desde la firmeza de dicha resolución, esto es, cuando no se interpongan recursos, cuando los interpuestos se hayan decidido o cuando se renuncie expresamente a ellos (C. P. A. C. A., art. 87, antes C. C. A., art. 62).

En concepto del máximo tribunal de lo contencioso administrativo,

el término con el que cuenta la administración para efectuar el pago efectivo del auxilio de cesantías es de sesenta y cinco (65) días hábiles siguientes al día de la presentación de la solicitud de su reconocimiento. Este término

1 "La vida diaria enseña que una persona especialmente en relación a [sic] los servidores públicos comienza un largo proceso de burocracia y de tramitología para lograr el cobro de sus cesantías, bien porque requiera la liquidación parcial o porque ha terminado su vinculación laboral con la administración; circunstancias estas que traen consigo, como es sabido, la posibilidad y efectividad de corrupción, porque ante la necesidad económica del trabajador, se hace presente la mordida o coima para los funcionarios que están en la obligación de hacer esos trámites [...]. Además de este factor de corruptela y tras la tortuosa espera, cuando al final se paga al trabajador su cesantía, tan solo se le entrega lo que certificó la entidad patronal meses y hasta años atrás al momento de la liquidación. Ni un peso más” (Congreso de la República, 1995, p. 1). 
comprende quince (15) días hábiles para expedir la Resolución de Liquidación de las Cesantías definitivas, cinco (5) días hábiles de su ejecutoria, y cuarenta y cinco (45) días hábiles para efectuar el pago de la prestación social. (Consejo de Estado, 30 de julio de 2009)

La Ley 1437 de 2011 amplió a diez días el plazo para incoar los recursos de reposición y apelación contra los actos administrativos, así que la autoridad actualmente cuenta con setenta días hábiles a partir de la formulación de la solicitud de cesantías para efectuar el pago correspondiente, término al cabo del cual se causa la sanción consagrada en el parágrafo del art. 5 de la Ley 1071 de 2006:

En caso de mora en el pago de las cesantías definitivas o parciales de los servidores públicos, la entidad obligada reconocerá y cancelará de sus propios recursos, al beneficiario, un día de salario por cada día de retardo hasta que se haga efectivo el pago de las mismas [sic], para lo cual solo bastará acreditar la no cancelación dentro del término previsto en este artículo.

En tal sentido, resulta pacífico entender que se trata de una medida instituida para castigar severamente al empleador moroso que vulnera el derecho del ex servidor público a percibir sin retraso la liquidación definitiva de sus cesantías, o del trabajador activo que requiere oportunamente el retiro parcial de la prestación para solventar sus necesidades, $v$. gr., en materia de vivienda y educación (art. 3) ${ }^{2}$.

Sin embargo, trascurrida más de una década no ha existido similar claridad en cuanto a la cuerda procesal a través de la cual se debe deprecar la referida indemnización de imbricación prestacional. Veamos.

Desde su significación más general, se entiende por jurisdicción "la soberanía del Estado, aplicada por conducto del órgano especial a la función de administrar justicia

2 Pese a algunos pronunciamientos aislados para el caso específico de los docentes oficiales (Consejo de Estado, 19 de enero de 2015), ha sido tesis mayoritaria que tanto a estos como a los demás empleados y trabajadores públicos les es aplicable la Ley 1071 de 2006 como garantía del reconocimiento pronto y oportuno del auxilio de cesantía (arts. 13 y 53 de la Constitución). Sobre el tema igualmente se ha pronunciado la Corte Constitucional. (Sentencia SU-336/2017) 
[...] mediante la aplicación de la ley a casos concretos, de acuerdo con determinados procedimientos y mediante decisiones obligatorias" (Devis Echandía, 1961, p. 175). Como facultad de "decir el derecho" es una sola, indivisible y reposa en todos los funcionarios a quienes la ley la ha asignado. Cuestión distinta, como lo precisa López Blanco, es "que por razones de orden práctico se institucionalizó la utilización del vocablo como sinónimo de competencia", desde luego que cuando el ordenamiento alude a falta de jurisdicción en realidad "se está refiriendo a falta de competencia por ramas" (2009, p. 139).

Adviértase desde ya que los conflictos jurisdiccionales, de ordinario suscitados entre funcionarios adscritos a ramas diferentes dentro del poder judicial, o en términos de la Ley 270 de 1996, Estatutaria de Administración de Justicia, "de competencia que ocurran entre las distintas jurisdicciones", actualmente continúan siendo dirimidos por la Sala Jurisdiccional Disciplinaria del Consejo Superior de la Judicatura (num. 2, art. 112). Si bien el art. 14 del Acto Legislativo 2 de 2015 modificó el art. 241 de la Constitución Política atribuyendo dicha función a la Corte Constitucional, la Sala Plena de esta corporación puntualizó que mientras los magistrados que habrán de integrar la Comisión Nacional de Disciplina Judicial no se posesionen en sus cargos —ello no ha ocurrido-, la mencionada sala del C. S. de la J. seguirá desempeñando plenamente sus funciones (C. Const. Auto 278/2015).

Pero denomínese ausencia de competencia o de jurisdicción, y despejado quién ha resuelto y cuál órgano desatará a futuro dichos conflictos — tan latentes en este asunto como más adelante se explicará-, lo cierto es que el ordenamiento adjetivo contempla dos mecanismos para ventilar el pago de la sanción en comento.

Por un lado, el medio de control de nulidad y restablecimiento del derecho ante la jurisdicción de lo contencioso administrativo (C. P. A. C. A., art. 138, antes C. C. A., art. 85), de naturaleza subjetiva, individual, temporal y desistible (Santofimio Gamboa, 2004), orientada en este contexto a derribar la legalidad del acto de la administración pública, expreso o presunto, que ha negado el otorgamiento de la indemnización por pago tardío de cesantías y abre así paso al resarcimiento del daño. 
Mírese que el num. 4 del art. 108 del compendio vigente asigna a dicha jurisdicción la función de dirimir los conflictos "relativos a la relación legal y reglamentaria entre los servidores públicos y el Estado, y la seguridad social de los mismos [sic], cuando dicho régimen esté administrado por una persona de derecho público”. Así que se trata de un juicio eminentemente declarativo pues conforme a lo dispuesto en el num. 7, el contencioso administrativo sólo es competente para conocer de ciertos procesos ejecutivos (los derivados de las condenas impuestas y las conciliaciones aprobadas por esa jurisdicción, los provenientes de laudos arbitrales donde hubiere sido parte una entidad estatal y los originados en contratos celebrados por estas).

No sobra acotar que la pretensión de nulidad y restablecimiento del derecho se halla condicionada a su interposición tempestiva, cuatro meses desde la ejecutoria del acto en que la autoridad se niega a reconocer la sanción o contados a partir de la configuración del acto ficto, so pena de que opere la caducidad (C. P. A. C. A., art. 164, num. 2, lit. d). También al previo agotamiento de la conciliación prejudicial como requisito de procedibilidad ${ }^{3}$, al ser la indemnización en mención un asunto susceptible de "transacción [...] desistimiento y conciliación", de tinte netamente económico y "de carácter particular, no general y abstracto" (Legis Editores, 2012, p. 325).

El otro camino de reclamación es el proceso ejecutivo laboral ante la jurisdicción ordinaria especializada laboral y de la seguridad social, habida cuenta de que el art. 2 del C. P. T. y S. S., modificado por el canon 2 de la Ley 712 de 2001, le adjudicó competencia general para conocer de "la ejecución de obligaciones emanadas de la relación de trabajo y del sistema de seguridad social integral que no correspondan a otra autoridad". Por consiguiente, la copia del acto administrativo de reconocimiento de las cesantías — donde además puede constar la data de solicitud_-, la prueba del salario tenido en cuenta para calcular la prestación social y la acreditación del pago

3 Fueron varias las dificultades relacionadas con la conciliación en materia de lo contencioso administrativo desde su diseño en el art. 64 de la Ley 446 de 1998. Fue el art. 13 de la Ley 1285 de 2009 la disposición que de una vez por todas determinó su carácter ineludible para la formulación de los medios de control de nulidad y restablecimiento del derecho, reparación directa y controversias contractuales. Se trata de un mecanismo alterno que ha de adelantarse exclusivamente ante los agentes del Ministerio Público (procuradores delegados ante el Consejo de Estado y procuradores judiciales I y II), y que de fructificar requiere aprobación judicial. 
inoportuno de esta bien pueden constituir un título ejecutivo complejo de carácter laboral (art. 100) $)^{4}$.

El panorama expuesto arroja una conjetura inicial: aunque bien encaminada la estipulación legal de la sanción, no atinó el legislador en el sentido de establecer diáfanamente cuál sería la manera de exigirla. Si lo perseguido era una respuesta ágil, imparcial y efectiva a las solicitudes de pago de las cesantías, la más elemental previsión debió consistir en fijar ab origine un único cauce de reclamación del castigo.

Inclusive, para precaver la duplicidad de instrumentos de defensa hubiese bastado que el parágrafo del art. 5 de la Ley 1071 de 2006 prescribiera que el órgano que inobservase los términos referidos debía dar impulso oficioso al procedimiento administrativo dirigido a examinar el otorgamiento de la sanción. Ello implicaría cumplir, desde luego, "con los principios de la actuación administrativa y especialmente el de publicidad, en cuanto a que [...] dichas actuaciones, deben ser comunicadas a los terceros que puedan resultar afectados con las mismas [sic]" (Güechá Medina, 2016, p. 400).

De ese modo encontrarían solución varios problemas liminares: i) al asignarse a la entidad la obligación de iniciar el trámite administrativo ante el mero hecho de la tardanza, de entrada se definiría el tratamiento exclusivo del asunto en sede "gubernativa"; ii) en consecuencia, el eventual control judicial del acto correspondería a la jurisdicción contencioso administrativa sin que pudiese ya tener cabida acudir directamente al juez del trabajo en acción ejecutiva; iii) causas resarcitorias idénticas recibirían igual tratamiento y iv) seguido ese derrotero uniforme, encontraría plena satisfacción la finalidad de institucionalización de la indemnización, a saber, asegurar el pago tempestivo del auxilio como derecho irrenunciable de los trabajadores.

4 La obligación no necesariamente debe constar en un solo documento, "pues es claro que es posible acudir a otros, e incluso a distintos medios de prueba, para suplir la deficiencia probatoria de aquel, caso en el cual se está en presencia del denominado título ejecutivo complejo" (Tribunal Superior del Distrito Judicial de Bogotá, 11 de julio de 2005). 
La complejidad viene dada porque, en ausencia de tal orientación normativa, ha sido sistemática la negativa de las entidades públicas para otorgar la sanción en sede administrativa. Además, es cardinal decirlo, el ya anunciado escenario de conciliación como antesala al proceso judicial — cuya teleología es acercar las posiciones de los adversarios hacia una solución negociada, evitar litigios innecesarios y reducir la congestión judicial — se ha reducido a un escalón netamente formal sin efecto decisivo en la formulación de propuestas de arreglo o de espacio de diálogo entre autoridad y servidor.

Lo anterior, en gran medida debido a que la posición institucional, materializada a través de los comités de conciliación de las entidades, continúa siendo negar la pretensión a toda costa, aun cuando el fundamento resulte tozudo y abiertamente desprovisto de asidero jurídico y fáctico, en vez de intentar, si es que el derecho del quejoso es inexpugnable - lo cual es fácilmente identificable_-, proponer correctivos al conflicto a través de recíprocas concesiones. Al fin y al cabo esta salida consensuada se considera mucho más provechosa tanto para el derecho subjetivo alegado como para el patrimonio público en términos de celeridad y economía.

Aunque no es aquel el único escollo ${ }^{5}$ y en esa dirección Bermejo Galán propone:

Tanto el Ministerio de Justicia como la Procuraduría General de la Nación deberían implementar campañas cuyo fin sea contribuir con un cambio de mentalidad o de cultura de los ciudadanos y entidades estatales. Se debe tener en cuenta que Colombia es un país litigioso por tradición y convicción, que considera más rentable un proceso largo y tedioso, que buscar un mecanismo alterno de resolución de conflicto. (2015, pp. 119-120)

5 Algunos elementos adicionales, según se plantea, serían decisivos para la efectividad del mecanismo: i) que "el solicitante aportara la mayor cantidad de información posible en forma clara y con las pruebas correspondientes" y los abogados morigeren la propensión a la judicialización del conflicto; ii) que la entidad convocada "busque el uso plural de la comunicación con el solicitante y el conciliador, con el fin de examinar una estrategia” y iii) que los agentes del Ministerio Público tomen un verdadero rol activo para "incentivar acuerdos conciliatorios justos”, propósito que se alcanzaría al sugerir fórmulas de acuerdo o inclusive "solicita[ndo] al comité de conciliación que reconsidere sus decisiones cuando a ello haya lugar con el fin de garantizar que al acuerdo a que lleguen las partes también sea beneficioso para el interés general” (Bermejo Galán, 2015, pp. 119-121). 
Todos los factores anotados concentraron la salida a este tipo de controversias en el ámbito jurisdiccional, que contrario a lo esperado profundizó la incertidumbre en evidente desmedro de los derechos de los servidores estatales a la igualdad y el acceso a una justicia pronta y material.

En principio pareciera que el texto de las leyes citadas ut supra apunta, cuando indica que "bastará acreditar la no cancelación dentro del término previsto", a que la acción pertinente es la ejecutiva laboral, en una especie de causación automática del derecho indemnizatorio cuyo origen no es el acto administrativo que otorga las cesantías sino la propia ley, esto es, la tardanza reprochada en el parágrafo del art. 5, cuya redacción permitiría al acreedor perseguir ejecutivamente una obligación clara, expresa y exigible a razón de un día de salario por cada día de retardo.

No obstante, el tema no resulta para nada pacífico. Muestra de ello son las varias posturas jurisprudenciales edificadas en torno a la jurisdicción llamada a decidir los litigios de marras.

A partir de 2007 el Consejo de Estado abandonó el criterio que desde 1998 admitía la procedencia de la acción de reparación directa para deprecar la indemnización de los daños emanados de la demora de la administración en reconocer el auxilio de cesantía ${ }^{6}$.

Modificando esa tesis, la Sala Plena de lo Contencioso Administrativo unificó su criterio y asentó que la acción a entablar, dependiendo de la tipología del caso, en unos eventos será la de nulidad y restablecimiento del derecho y en otros, la ejecutiva ante la jurisdicción ordinaria, bajo varias hipótesis: si el afectado disiente de la resolución de otorgamiento de la prestación social naturalmente hay lugar

6 En dicho periodo consideró la Colegiatura que "la orden de pagar una prestación social como la cesantía, es un acto de la administración que realiza una norma legal que modifica por tanto el ordenamiento jurídico”, mas la actuación material consistente en la ejecución de ese acto configura una operación administrativa, "y si esta se produce en forma tardía y de ello se deriva un perjuicio al beneficiario del derecho, se concluye que la fuente de producción del daño no es entonces el acto, sino la operación” (Consejo de Estado, 23 de febrero de 1998). En otros casos, paralelamente, sostuvo una postura diferente estimando procedente la ejecución laboral (Consejo de Estado, 17 de julio de 1997), a tal punto que se declaró inhibida en alguna ocasión y envió el expediente al juez del trabajo (Consejo de Estado, 31 de julio de 2003). 
a enfilar la primera, igualmente si se cuestiona el contenido mismo del acto de reconocimiento de la sanción moratoria; pero si no hay controversia, el acto que reconoce la cesantía configura un título ejecutivo "y puede ser reclamado por la vía judicial correspondiente, que es la acción ejecutiva, pero en lo que respecta a la sanción moratoria deberá demostrarse, además, que no se ha pagado o que se pagó en forma tardía". A la vez, "cuando se suscite discusión sobre algunos de los elementos que conforman el título ejecutivo, como que no sean claros, expresos y exigibles, debe acudirse ante esta jurisdicción [administrativa] para que defina el tema" (Consejo de Estado, 27 de marzo de 2007). Providencia reiterada en abundantes pronunciamientos posteriores ${ }^{7}$.

A pesar de su aparente precisión, los citados postulados no despejan del todo algunos interrogantes. ¿La resolución que otorga el auxilio de cesantías es suficiente para iniciar el proceso ejecutivo por la sanción moratoria? En ese caso, ¿la mora podría discutirse y enervarse en sede de excepciones? A la par surge incertidumbre en cuanto a si obligatoriamente debe utilizarse el medio de nulidad y restablecimiento del derecho cuando se ha formulado petición previa de reconocimiento de la indemnización y existe acto administrativo expreso o ficto que la niega. O lo que es lo mismo, ¿podría adelantarse la ejecución ante el juez del trabajo ignorando ese pronunciamiento de la Administración?

No se comparte, eso sí, la premisa consignada por tal corporación, según la cual para la configuración de un título ejecutivo complejo de carácter laboral no basta la norma como fuente de la obligación, sino que debe contarse con el utópico pronunciamiento o reconocimiento de lo adeudado por parte de la Administración.

No existe antecedente alguno en ese sentido. No se requiere tal reconocimiento expreso por parte del deudor ya que teniendo la sanción naturaleza accesoria, se entiende inherente a la obligación principal. Mal podría esperarse que el obligado vaya a expedir un acto donde reconozca su propia incuria, máxime por las acciones de

7 Ver, entre las numerosas decisiones proferidas por la Sección Segunda, Subsección A, Consejo de Estado, 20 de octubre de 2014; Consejo de Estado, 16 de julio de 2015; Consejo de Estado, 1 de diciembre de 2016; Consejo de Estado, 22 de marzo de 2018. 
repetición a que podría haber lugar. Además, se torna desmedido exigir la anuencia específica del deudor habida cuenta de que la sanción está claramente prevista y es determinable en su base y monto conforme a los días de retardo. A título ilustrativo destáquese, $v$. gr., que en materia comercial los intereses moratorios (C. Co., art. 884) no requieren pactarse en el título valor y mucho menos que una vez presentada la mora el deudor deba reconocer que los adeuda pues el acreedor se legitima presentando el cartular contentivo de la obligación principal y la prueba, incluso la mera afirmación, de que el capital se canceló tardíamente o no se pagó, sin más8.

Del mismo modo, vale la pena destacar la dificultad de aplicación en el terreno práctico de algunas de aquellas reglas, pese a su gran utilidad.

Ciertamente, un considerable número de jueces administrativos, frente a súplicas de declaración de nulidad del acto administrativo mediante el cual se ha negado el reconocimiento y pago de la sanción moratoria, al no discutirse la validez de la resolución que otorgó las cesantías parciales o definitivas y ante la acreditación fehaciente de su cancelación extemporánea, arguyen que la competencia recae en los jueces laborales y se declaran sin jurisdicción. Otros juzgadores privilegian la vía de nulidad y restablecimiento del derecho elegida por el actor, admiten la demanda y dan curso al asunto, bien hasta la audiencia inicial pues a veces se declara próspera la excepción previa de falta de jurisdicción propuesta por la demandada y en menor número de casos continúa el proceso hasta dictarse sentencia.

A su vez, cuando el reclamante acude directamente a la acción ejecutiva aduciendo la existencia de un título complejo o cuando el expediente es remitido por el juez administrativo por incompetencia, algunos jueces laborales libran el mandamiento de pago pedido siempre que el solicitante pruebe el reconocimiento de las cesantías y el hecho de que no se le ha pagado o que el pago fue extemporáneo (por ejemplo, en el Distrito Judicial de Santa Rosa de Viterbo, hasta mediados de 2017). Mas en su

8 Profundiza en ello con destacable claridad y expone otras motivaciones y argumentos la H. M. Ana Lucía Caicedo Calderón en salvamento de voto emitido dentro de contienda ejecutiva laboral (Tribunal Superior del Distrito Judicial de Pereira, 27 de octubre de 2015). 
mayoría, como generalmente ocurre en el Distrito Judicial de Bogotá, los falladores precisan carecer de jurisdicción y formulan entonces el conflicto negativo.

La tesis de la Sala Disciplinaria del Consejo Superior de la Judicatura, al resolver tales colisiones entre las jurisdicciones ordinaria y contencioso administrativa, comenzó por plegarse a la indicada posición del C. de Estado puesto que

en casos [en los que] la acreencia laboral [cesantía] ya fue reconocida por la administración, y como quiera que no se está discutiendo la legalidad del acto administrativo que la reconoció, sino muy por el contrario el pago de los intereses [...] es indudable que la demandante debe acudir a la jurisdicción ordinaria. (Consejo Superior de la Judicatura, 1 de junio de 2011)

Empero, en abundantes pronunciamientos posteriores contradictoriamente el tribunal disciplinario entendió que el conocimiento debía adscribirse conforme a la acción elegida por el demandante pues si se acudía al medio de control de nulidad y restablecimiento del derecho, ello demarcaba, sin más, la competencia del contencioso administrativo, mientras que si se impetraba demanda ejecutiva, el asunto correspondía al resorte del juez del trabajo. Consideraciones que el Consejo Superior de la Judicatura (3 de diciembre de 2014) revaluó en orden a "que no es el nomen juris de la demanda lo que determina la jurisdicción del proceso, sino la real pretensión y objeto del litigio".

Esta decisión igualmente denotó un distanciamiento de la regla que en líneas antecesoras fue interpelada ${ }^{9}$, amén que

ya no es defendible la posición esbozada en el sentido que por no tener un reconocimiento expreso la sanción moratoria por parte de la administración, no puede pregonarse la existencia de título ejecutivo, cuando la complejidad del mismo [sic] deviene de la presencia de elementos básicos e ineludibles, como la existencia del reconocimiento de las cesantías (no se discute la misma

9 En esa misma línea decisoria y argumentativa, $v$. $g r$. Consejo Superior de la Judicatura, 5 de agosto de 2013; Consejo Superior de la Judicatura, 20 de abril de 2016. 
[sic]), su pago tardío o no pago y la ley misma (Ley 244 de 1995 y Ley 1071 de 2006) como fuente de obligación que es, ante esas realidades no hay forma de sustraerse al reconocimiento de título ejecutivo, que por serlo, es exigible ante la jurisdicción que competa, solo que ante los supuestos dados en el artículo 104-5 de la Ley 1437 de 2011, casos como el presente no son de los enlistados allí por el legislador, por lo tanto, el juez natural sigue siendo el ordinario laboral.

[...] Diferente fuera que se estuviera discutiendo el reconocimiento de las cesantías como litigio a resolver por alguna de las jurisdicciones enfrentadas, pero una vez declarado y reconocido el derecho de las primeras, la ley, como se dijo, estipula la cuantía como castigo que se debe pagar por no cancelar dentro del periodo de gracia para ello concebido, consagración esta que refuerza el argumento de estar frente a cuantías determinadas y ejecutables, no por otra vía distinta a la laboral ordinaria. (Consejo Superior de la Judicatura, 3 de diciembre de 2014)

Este vaivén de postulados e imprecisiones, con los matices y "espacios grises" que se han pretendido sintetizar, abrió paso a un desbordamiento del ámbito razonable de independencia y autonomía judicial consagrado en el art. 228 C. P., ya que la suerte de cada proceso ha dependido de los abundantes criterios, reglas y excepciones aplicables, el momento en que se ha iniciado, la postura que cada juez adopte dentro del amplísimo espectro decisorio, la tesis aceptada en el distrito judicial respectivo, la disyuntiva entre obedecer el precedente vertical o lo decidido en pugnas de competencia y la peligrosa aplicación de modificaciones del precedente a procesos en curso, entre otros factores.

Indudablemente, en todo sistema jurídico es inevitable la interpretación disímil y variada de las normas legales por parte de los jueces. Sin embargo, Marinoni acertadamente puntualiza:

La interpretación, al tender a un único significado, se aproxima al ideal de la previsibilidad. Eso no quiere decir que la eliminación de la duda interpretativa es factible, pero que [sic] sí que se pueden y deben minimizar, en la medida de 
lo posible, las divergencias interpretativas acerca de las normas, colaborándose, de tal suerte, para la protección de la previsibilidad, indispensable al encuentro de la seguridad jurídica. (2012, p. 254)

En nuestro tema de estudio esas diversas elucidaciones, contrario a minimizar sus contrastes con miras a proporcionar estabilidad y continuidad en el sentido de las determinaciones judiciales, trascendieron en verdaderas brechas llegando a un punto tan delicado que un importante número de conflictos está quedando irresoluto. Tal circunstancia es inadmisible porque, como lo enseñan los profesores García de Enterría y Fernández, "si los ciudadanos no pudiesen interponer a la Administración la observancia de las leyes, estas carecerían de verdadera eficacia [...] serían meras admoniciones morales o de buena conducta deseable, no verdaderas normas vinculantes para ella” (2006, p. 37).

Expliquémoslo: cuando el reclamante elige concurrir ante el juez laboral, mientras este examina la demanda ejecutiva y adopta la decisión correspondiente podría simultáneamente fenecer el término de caducidad del medio de control de nulidad (C. P. A. C. A., art. 138, inc. 2), más aún si se libra el mandamiento de pago pero posteriormente el funcionario decide variar su criterio declarando probada alguna excepción "de mérito" y termina el proceso ${ }^{10}$. A ese tenor, si el interesado ya había solicitado ante la administración el otorgamiento de la sanción, en principio perdió la instancia de accionar ante el juez administrativo, y si no había acudido, el menoscabo temporal para que se atienda su queja habrá alcanzado entre uno y tres años.

10 Hipótesis actualmente de común y desafortunada ocurrencia. Cítese, por ejemplo, un proceso ejecutivo laboral de primera instancia en el cual el autor del presente manuscrito funge como apoderado del demandante. Se solicitó la indemnización moratoria a la administración y fue negada el 11 de febrero de 2016; se acudió a la conciliación prejudicial y tras resultar fallida, a la jurisdicción contencioso administrativa a través del medio de control de nulidad y restablecimiento del derecho. Empero, el Juzgado Segundo Administrativo del Circuito de Sogamoso (Boyacá) declaró carecer de jurisdicción y ordenó la remisión del instructivo a los jueces laborales (22 de agosto de 2016). Adecuada la demanda, el 15 de diciembre de 2016 el juez del trabajo libró mandamiento de pago considerando que los documentos allegados configuraban título ejecutivo complejo, pero con posterioridad, en audiencia especial de decisión de excepciones, abruptamente declaró probada la de "inexistencia de título ejecutivo" con apoyo en que su superior funcional había cambiado de criterio sobre el asunto habida cuenta de que lo hizo también el Consejo Superior de la Judicatura, Sala Disciplinaria (Juzgado Primero Laboral del Circuito de Sogamoso, 15 de junio de 2018). La decisión se encuentra en trámite de apelación ante la Sala Única del Tribunal Superior del Distrito Judicial de Santa Rosa de Viterbo. 
Deterioro que igualmente acaece cuando el primer camino es el medio de control de nulidad y ab initio el juez administrativo no declara su carencia de jurisdicción, esto es, si ello solamente ocurre al decidir excepciones previas o, en el peor de los casos, cuando tramita la causa pero niega las pretensiones por motivos insustanciales. Inclusive se conocen eventos donde la primera instancia profiere sentencia estimatoria y el tribunal administrativo, llegadas las diligencias de apelación, se declara incompetente y remite el asunto a los juzgadores laborales ${ }^{11}$ en clara mengua de las garantías superiores del gestor del litigio ${ }^{12}$.

En definitiva, de poco o nada sirve que el sistema jurídico brinde herramientas para remediar el atraso en el pago de cesantías y establezca unos criterios funcionales de distribución de competencias, y que la jurisprudencia fije el alcance de esas reglas, si ello no conduce a un sendero uniforme. $\mathrm{O}$ en otros términos, si la realidad no interpreta el contenido del precepto supralegal al debido proceso estatuido en el canon 29 de la norma de normas.

El acceso a la administración de justicia implica, a voz del pregón de la Sentencia C-037/1996 de la Corte Constitucional,

la posibilidad de que cualquier persona solicite a los jueces competentes la protección o el restablecimiento de los derechos que consagran la Constitución y la ley. Sin embargo, la función en comento no se entiende concluida con la simple solicitud o el planteamiento de las pretensiones procesales ante las respectivas instancias judiciales; por el contrario, el acceso a la administración de justicia debe ser efectivo, lo cual se logra cuando, dentro de determinadas circunstancias y con arreglo a la ley, el juez garantiza una igualdad a las partes, analiza las pruebas, llega a un libre convencimiento, aplica la Constitución

11 En un caso de contornos similares fueron amparados los derechos del accionante pues si "se fija en un momento determinado una tesis jurisprudencial sobre la acción idónea para reclamar un derecho, no es razonable asaltar en su buena fe al demandante con un cambio imprevisto de criterio, más aún, si [...] la litis ya se encontraba admitida y la primera instancia decidió el fondo del asunto" (C. Const. Sentencia T-198/2018).

12 En tales eventos luce indefendible el desgaste de la administración de justicia y el valioso tiempo que el servidor público habrá perdido, sin contar con el efecto radical que podría ocasionar la prescripción trienal de derechos laborales y una eventual consideración de cosa juzgada, dependiendo del caso específico. 
y la ley y, si es el caso, proclama la vigencia y la realización de los derechos amenazados o vulnerados.

No ha de dejarse de lado la importante doctrina patria y foránea que en voces de los más reputados procesalistas ha esbozado las diferencias entre la acción, el derecho material subjetivo y la pretensión. Sin embargo, para los efectos del tema que se viene tratando cumple subrayar, por la interdependencia entre estas instituciones, que el debido proceso se ve seriamente truncado en su núcleo esencial cuando las posibilidades de los afectados con la tardanza en la consignación del auxilio de cesantía se limitan a contar, en el papel, con el derecho a entablar sus súplicas ante la administración de justicia, pero ello no desemboca en un camino de solución real y certero, consistente y determinable. ¿¿De qué garantía judicial hablamos si no hay univocidad frente a la acción procedente para obtener la declaración o la satisfacción coactiva de los derechos subjetivos? De ninguna.

Para Couture (1966), el poder que tiene todo sujeto de derecho de acudir a los órganos jurisdiccionales para reclamar la satisfacción de una pretensión tiene un inescindible carácter público. Tal connotación adosa al proceso judicial el propósito de que el conflicto culmine con una determinación que interprete la vigencia del interés general.

Lo medular no es, pues, que absolutamente todas las reclamaciones judiciales sean favorables a quienes obtuvieron el pago de sus cesantías tardíamente, "sino el interés de que el litigio tenga una justa composición” (Devis Echandía, 1961, p. 342). Con ello se alude a que una de las finalidades públicas esenciales, la de asegurar la vigencia de los derechos y garantías de los asociados, se incumple cuando la aspiración indemnizatoria no cuenta con una vía procesal transparente, coherente y predecible.

Considérese que la explicitada incertidumbre en cuanto a la jurisdicción llamada a definir tales controversias riñe con la salvaguarda de valores y principios fundacionales de todo Estado social de derecho.

La aplicación dispersa, inconsistente y sorpresiva de las normas legales y jurisprudenciales sobre la materia vulnera el art. 13 de la Constitución y puede 
transformar la autonomía judicial en arbitrariedad. Téngase presente, como lo rotula De Otto, que

la libertad del juez [en la aplicación del derecho] lesiona el principio de igualdad en la medida en que permite que casos iguales sean resueltos de manera distinta por un mismo juez o por varios, introduciendo así un factor de diversificación del que puede resultar que la ley no es igual para todos. (1995, p. 290)

En ese sentido, conviene evocar que la existencia del precedente se soporta en la necesidad de justificar las decisiones judiciales en forma sistémica. Es deseable, entonces, un mínimo de certidumbre en la manera como los jueces interpretan y resuelven las acciones encaminadas a resarcir la tardanza en la consignación de cesantías de los servidores públicos.

Desde luego, la disciplina de precedentes no es pétrea ni fosiliza los dictados jurisprudenciales; como fuente de derecho su contenido preceptivo o interpretativo es susceptible de variación y evolución a condición de cumplir con la carga argumentativa demostrativa de las razones que justifican el cambio ${ }^{13}$. Sería un dislate aseverar que el Consejo de Estado o el propio tribunal conflictual no están habilitados para revisar su jurisprudencia y de estimarlo apropiado modificar su criterio. Pero las tesis originarias y las actuales, tanto como los eventuales cambios, no deben suponer postulados antagónicos ni aquellas reformas han de implicar, sin más, el automático fracaso de las acciones en curso que fueron iniciadas siguiendo la postura anterior, a riesgo de afectación del derecho de acceso a la administración de justicia.

Dentro del núcleo de protección del debido proceso lo jurídico y lo pragmático reclaman la adopción de una postura estable y uniforme, que se traduzca en que las pretensiones en comento sean abordadas por la jurisdicción competente bajo

13 "Para que un cambio jurisprudencial no sea arbitrario es necesario que el tribunal aporte razones que sean de un peso y una fuerza tales que, en el caso concreto, primen no solo sobre los criterios que sirvieron de base a la decisión en el pasado sino, además, sobre las consideraciones de seguridad jurídica e igualdad que fundamentan el principio esencial del respeto del precedente en un Estado de derecho”. (C. Const. Sentencia C-400/1998) 
reglas claras y anticipables, entre otros argumentos, porque la previsibilidad de las determinaciones del poder judicial otorga certeza sobre el contenido material de los derechos y las obligaciones.

Atinadamente se ha afirmado:

La razón para seguir los precedentes se encuentra en los beneficios que con ello se obtienen: la uniforme aplicación de las leyes, la economía procesal, la predicción de las decisiones judiciales, la seguridad jurídica y el prestigio de los jueces y tribunales, entre otros. Según el argumento de justicia formal, la razón para seguir los precedentes es el principio de igualdad, es decir, que casos iguales requieren un tratamiento semejante. La igualdad como principio moral básico incluye no solo a los iguales en un momento contemporáneo, sino a los que nos precedieron y a los que nos seguirán en el tiempo. (Moral Soriano, 2002, pp. 128-129)

Así las cosas, cualquier afectado por la mora del empleador estatal en el pago de cesantías debe contar con la posibilidad de acudir a la sede judicial y obtener un pronunciamiento al respecto, de modo que el fallador de la respectiva causa consulte el panorama de decisiones legítimas que le anteceden atendiendo al necesario y armónico criterio de cierre y dejando a salvo, por supuesto, las precisas y exigentes circunstancias en que el funcionario puede distanciarse de la aplicación de la subregla en vigor ${ }^{14}$. Mas esto no puede obedecer, como ha venido sucediendo en estos años, a un ejercicio de subsunción o interpretación absolutamente extenso. Es decir, la elección de la solución no puede ser la que le parezca más útil al cognoscente dentro de un verdadero abanico de posturas a veces contrapuestas y vacilantes.

Volviendo la mirada hacia el replanteamiento del "papel que cumple la función judicial en el establecimiento del derecho vigente, bajo el entendido de que el juez

14 Los funcionarios judiciales pueden apartarse de forma razonable y legítima de los precedentes ante la existencia de diferencias significativas o disanalogía fáctica que amerite un trato jurídico distinto, bien cuando hay lugar a ampliar o restringir el alcance de la subregla, bien al distinguir entre obiter dictum y ratio decidendi o también al presentarse indeterminación en la jurisprudencia (López Medina, 2006). 
deja de ser operador jurídico para tornarse en creador de subreglas que concretan el contenido y alcance de la normatividad vigente" (Parra, 2004, p. 252), lo pertinente es examinar, identificar y si es del caso extender la aplicación de la ratio decidendi disponible en el ordenamiento, que se supone pacífica y se halla delimitada por los patrones fácticos abordados en los casos anteriores. Como es sabido, el aspecto factual es la génesis de la fuerza vinculante del precedente: aplicar la misma regla a quienes se hallen en idéntica situación de hecho.

Según esas premisas, con todo y que el autor de este manuscrito, itérese, no comparte la posición concerniente a que el servidor estatal requiere de acto de reconocimiento de la sanción moratoria que le sirva de título ejecutivo ante la jurisdicción ordinaria laboral, hay que advertir que resultó bastante afortunada la emisión de la decisión calendada 16 de febrero de 2017 por parte del tribunal de conflictos, porque aunque justamente acoge ese raciocinio, que ya el C. de Estado pregonaba tiempo atrás, contribuyó a despejar el camino para remediar de una vez por todas el laberinto en que se ha convertido la resolución de las acciones encaminadas a resarcir este tipo de perjuicios.

Con carácter de unificación jurisprudencial, entonces, la Sala Jurisdiccional Disciplinaria reseñó que

por la importancia jurídica de estos asuntos que reiteradamente se han venido resolviendo, y con las finalidades de facilitar el acceso de los usuarios a la administración de justicia, de no entrar en controversia con las líneas jurisprudenciales que creen los órganos de cierre de las demás jurisdicciones, de crear un precedente vinculante para esta misma sala y para las autoridades en conflicto, a fin de que se convierta en un mecanismo de descongestión, que evite la proposición de conflictos sobre este tema, contribuya a la seguridad jurídica y a la creación de un precedente de obligatoria aplicación para todas las autoridades, decide en esta providencia UNIFICAR EL CRITERIO respecto de la autoridad competente en las demandas en las que se pretenda la declaratoria de mora en el pago de las cesantías, dejándolo de manera expresa, para efectos de su publicación y difusión por la relatoría de esta Sala, de manera sistematizada y organizada, asignando la competencia a la jurisdicción administrativa. (Consejo 
Superior de la Judicatura, 16 de febrero de 2017; cursivas en el original, mayúsculas ańadidas)

Sin duda, el protagonismo se adosa a la jurisdicción contencioso administrativa como regla general de competencia frente a los reclamos judiciales atańederos al otorgamiento de la sanción por tardanza en la consignación de cesantías parciales o definitivas. Y siendo coincidentes ahora sí las posturas del C. de Estado y el Consejo Superior de la Judicatura sobre el tema, es de esperar que todos los jueces de la república acaten la subregla consistente en que la vía procesal adecuada para discutir este tipo de controversias es el medio de control de nulidad y restablecimiento del derecho, salvo cuando exista acto administrativo de la autoridad reconociendo la sanción - ilusorio en el terreno práctico-, caso en el cual el camino será el proceso ejecutivo laboral.

Dicha sujeción dimana, por supuesto, del carácter obligatorio del precedente judicial:

Sin respeto por el precedente no resulta posible predecir el sentido de las decisiones judiciales, tener certeza sobre el alcance de la ley, actuar conforme a derecho, anticipar la conducta ajena, predecir la actuación de las autoridades públicas o establecer límites del poder estatal. (Arrázola Jaramillo, 2015, p. 8)

En suma, sin la observancia del precedente no hay seguridad jurídica. Tampoco se resguarda la coherencia y unidad intrínseca del ordenamiento cuando la jurisprudencia es confusa y ambigua, como así ha acontecido respecto de la pretensión indemnizatoria plurimencionada, amén que durante más de diez años legitimó una multiplicidad de interpretaciones que finalmente se tradujo en contradicciones ilógicas entre jueces singulares y colegiados, laborales y de lo contencioso administrativo, lo que afectó por demás la eficiencia y eficacia institucional.

Antes de culminar estas reflexiones evóquese que el ordenamiento jurídico, en cuanto sistema, en principio se caracteriza por su plenitud conforme a elementales directrices de previsión de hipótesis de hecho y sus consecuencias. Los pilares de estabilidad, seriedad y anticipabilidad del comportamiento futuro y de sus efectos, 
tanto para la autoridad como para los administrados, están inescindiblemente ligados a los principios de buena fe y confianza legítima.

En consecuencia, la aplicación e interpretación de las normas por los jueces - acá disposiciones sustanciales y sobre competencia-, aunque corresponde a una disciplina dinámica y cambiante en función de la realidad misma, necesita estar dotada de consistencia. Al seguir esos parámetros, el precedente contribuye a la certidumbre del ordenamiento y "por tanto, desarrolla los principios liminares del Estado, lo que explica, de un lado su estabilidad y no su construcción caprichosa o conveniente $\mathrm{y}$, de otro lado, la adopción de las modificaciones y adaptaciones en forma seria, serena y ponderada" (Corte Suprema de Justicia, 25 de junio de 2009).

Lo central, entonces, es la preeminencia de las prerrogativas iusfundamentales de quienes acuden a la administración de justicia. Perspectiva en la que cobra especial relevancia la preservación de la confianza legítima entendida como la protección de las expectativas de estabilidad. Tal intelección es doctamente expuesta por Castillo Blanco y de contera permite redondear uno de los corolarios de este escrito:

Se protege la convicción íntima del ciudadano en la estabilidad normativa y las actuaciones del Estado, sin llegar al extremo de la petrificación del ordenamiento jurídico, ni a su preservación indefinida por cuanto el derecho se construye diariamente, vive en su interpretación y aplicación por los jueces como garantes primarios de los derechos, libertades y garantías ciudadanas. (1998, p. 108)

Conforme a lo hasta aquí discurrido, se ve con buenos ojos el esfuerzo que hace poco más de un año se viene gestando entre los órganos de cierre por unificar la regla competencial sobre la pretensión sancionatoria originada en la mora en el pago de cesantías parciales o definitivas a servidores públicos. Asignada la cláusula general a la jurisdicción de lo contencioso administrativo obtienen remedio la mayoría de las vicisitudes narradas en párrafos predecesores: como en la práctica ninguna entidad va a expedir una resolución reconociendo que adeuda la sanción moratoria, es claro que la vía de reclamación por antonomasia es el contencioso de nulidad y restablecimiento del derecho, lo cual redunda en una aplicación razonable, consistente y uniforme. 
Además, el proceso declarativo brinda mayores beneficios a las partes en el ejercicio de sus derechos procesales, ora en las distintas etapas, ora en la propia actividad probatoria, ora en los medios de defensa del demandado. Sin dejar de lado que podría fortalecerse la institución de la conciliación prejudicial y terminar con las dañinas declaraciones de falta de jurisdicción, con lo que se ampararía la realización de la justicia material y el interés general.

Si prosigue el señalado derrotero, esto es, si hay univocidad y seriedad en la resolución judicial de estas controversias, si con ello se protege la expectativa verosímil, sensata y predecible de todo servidor público afectado por la tardanza en el pago del auxilio y, por supuesto, si no decide alguna alta corporación mutar su postura hacia un criterio ya abandonado - y se considera acá que no existe carga argumentativa que legitime retomar tesis anteriores, al margen de que sean compartidos o no los argumentos para desechar el proceso ejecutivo_-, solo así los derechos fundamentales en juego serán objeto de protección plena y efectiva.

Para finalizar, es conveniente hacer un llamado a la sensatez y mesura de los jueces laborales que actualmente tramitan procesos ejecutivos iniciados antes del viraje jurisprudencial de la Sala Disciplinaria del Consejo Superior de la Judicatura. Esto porque, como ya lo ha sostenido la guardiana del texto fundamental, aunque el nuevo precedente fijado por un(os) órgano(s) de cierre tiene aplicación — horizontal y vertical - general e inmediata, "afecta una actuación procesal que se inició al amparo del precedente anterior”. (C. Const. Sentencia SU-406/2016)

Por tanto, los efectos jurídicos de la tesis novedosa, que asigna la competencia al juez de la administración, no pueden extenderse de manera mecánica e irreflexiva. Ello viene sucediendo, reitérese, cuando, librada orden de pago con apoyo en precedente anterior, el auto que posteriormente decide excepciones olímpicamente determina que ya no existe título ejecutivo complejo aduciendo la modificación jurisprudencial, con el agravante de que muchos de esos casos se iniciaron ante la jurisdicción contencioso administrativa y fueron remitidos al juez del trabajo vía decreto de falta de jurisdicción. 
Lo que legal y constitucionalmente corresponde en estos escenarios es que al momento de proferir su decisión el fallador efectúe un análisis fáctico y de antecedentes procedimentales, y prudencialmente determine si el cambio jurisprudencial resultó definitivo en la afectación de derechos fundamentales "al modificar las reglas procesales con base en las cuales, legítimamente, habían actuado los sujetos procesales" (C. Const. Sentencia SU-406/2016). Las más de las veces, no quepa duda, el juez del trabajo deberá inaplicar el criterio jurisprudencial en vigor y por garantía del acceso a la administración de justicia, igualdad y tutela judicial efectiva, habrá de resolver basado en la tesis otrora imperante, comoquiera que el inc. 2 del art. 430 del C. G. P., aplicable por autorización del canon 145 del C. P. T. y S. S., impide volver sobre los requisitos del título ejecutivo. En últimas, como también lo tiene decantado la jurisprudencia en materia contenciosa administrativa,

el acceso efectivo a la justicia no puede asegurarse sobre la base de criterios inciertos acerca de la manera como se pueden hacer valer las pretensiones. De ahí que si la jurisprudencia de un órgano de cierre en un momento determinado señaló un derrotero y este es seguido por el usuario de la administración de justicia en materia de la acción pertinente para demandar, no puede luego sorprenderse a este último con abruptos cambios jurisprudenciales, que en últimas comprometan el núcleo esencial de su derecho fundamental de libre acceso a la jurisdicción. (Consejo de Estado, 4 de mayo de 2011)

\section{ConCLUSIÓN}

La afortunada creación legal de la sanción moratoria por tardanza en el pago de cesantías a servidores públicos se vio empañada por la ausencia de atribución del juez que habría de atender esos reclamos judiciales, asignación que tampoco logró claridad y consistencia según las reglas de competencia. Jueces laborales y contencioso administrativos, usuarios de la administración de justicia y litigantes acumulamos más de una década de confusión auspiciada por las posturas contradictorias, reglas, excepciones y cambios establecidos por el C. de Estado y la Sala Disciplinaria del C. S. de la J., panorama que ha desbordado la teleología y función esencial del precedente, mereciendo fundadas objeciones el hecho de que se fallen de las más 
diversas maneras, a lo largo de distritos y circuitos judiciales del país, situaciones sustancialmente idénticas.

Este estudio también explicitó que la tensión entre los órganos límite abrió un pernicioso boquete en el ordenamiento, que dejó en libertad a los falladores para escoger entre una multiplicidad de opciones interpretativas. La repercusión fue un constante "tira y afloje" de declaraciones de falta de jurisdicción, conflictos de jurisdicción, denegación de pretensiones por motivos adjetivos, etc. Inclusive muchos litigios no han tenido una resolución material, $v$. gr. por efecto de la caducidad del medio de control de nulidad, la prescripción de derechos laborales, la cosa juzgada, en fin. Todo ha ocasionado que la asunción del castigo y el propio pago efectivo de las cesantías quedaran dependiendo de la voluntad de la administración, en contravía de la finalidad perseguida por el par. del art. 5 de la Ley 1071 de 2006.

En el artículo se mostraron, grosso modo, las innegables y trascendentales vicisitudes a que se enfrentan los accionantes en cuanto a la admisión, tramitación y decisión de esta clase de controversias por las vías del proceso declarativo y ejecutivo. En efecto, aunque conceptualmente - y el autor de este trabajo es de ese parecer- a cargo de la administración puede perfectamente configurarse una obligación clara, expresa y exigible de pagar la referida indemnización — título ejecutivo complejo-, lo cierto es que la realidad se ha encargado de revelar, con independencia del rol o posicionalidad del operador jurídico, que la solución más adecuada y garantista es asignar definitivamente al contencioso administrativo el conocimiento de los conflictos en comento.

En esa dirección, resulta encomiable la naciente modificación jurisprudencial de la Sala Jurisdiccional Disciplinaria del C. S. de la Judicatura colocándose a tono con la tesis inicial del Consejo de Estado. Según se anotó, lejos de tener una connotación eminentemente procesal que privilegie un rigor formulario, el derecho de acción propende a la primacía de las garantías constitucionales, finalidad que solo puede lograrse si existe coherencia y seriedad en la labor aplicativa y hermenéutica de los jueces en la solución de los conflictos, para nuestro caso, en cuanto al camino procesal para reclamar el derecho resarcitorio reconocido en la ley sustancial. 
La idea que se defendió es la necesidad de un mínimo uniforme —interés general一, de suerte que si el servidor estatal se ampara en un criterio normativo y jurisprudencial que orienta la vía procedimental para hacer valer su pretensión indemnizatoria, no se le cierren en la práctica las puertas a la jurisdicción por cuenta de pronunciamientos coetáneos alejados de un discernimiento armónico; que no se frustre la aspiración admitiendo demandas y dando curso a procesos a sabiendas de que el ulterior criterio del despacho cognoscente será que carece de competencia, situación que al tenor de las explicadas pautas bien puede determinarse desde un comienzo; y por ese camino, que pretensiones y situaciones fácticas idénticas se diriman de la misma forma. De lo contrario se corre el riesgo de incurrir en arbitrariedad.

Se consideró esencial el resguardo de las expectativas legítimas de los empleados estatales afectados por el fenómeno denotado de que sus casos sean resueltos conforme a parámetros previsibles y consistentes dentro del marco apreciable, pero razonable y admisible, de autonomía funcional reconocida a nuestros jueces.

En síntesis, queda claro que nada garantiza mejor el acceso a la administración de justicia, el debido proceso, la igualdad, la certeza jurídica, la confianza legítima y la seguridad jurídica que un estamento jurisdiccional ejerciendo sus funciones a través de cauces procedimentales adecuados, idóneos, definidos, estables y efectivos de cara a la realización del derecho material, y a fortiori, a la integridad del orden jurídico.

\section{REFERENCIAS}

Arrázola Jaramillo, F. (2015). La seguridad jurídica ante la obligatoriedad del precedente judicial y la constitucionalización del derecho. Revista de Derecho Público, 34, 1-28. DOI: https://doi.org/10.15425/redepub.34.2015.19

Bermejo Galán, J. C. (2015). La conciliación extrajudicial contenciosa administrativa. Jurídicas CUC, 11(1), 101-124. DOI: https://doi.org/10.17981/juridcuc.11.1.2015.5 
Castillo Blanco, F. (1998). La protección de la confianza en el derecho administrativo. Madrid: Marcial Pons.

Congreso de la República de Colombia (5 de agosto de 1995). Exposición de motivos Ley 244/1995. Gaceta del Congreso, 4(225).

Consejo de Estado. Sentencia exp. 11376 (17 de julio de 1997). M. P. Jesús María Carrillo Ballesteros.

Consejo de Estado, Sección Tercera. Sentencia exp. 10813 (23 de febrero de 1998). M. P. Ricardo Hoyos Duque.

Consejo de Estado. Sentencia exp. 4873-2002 (31 de julio de 2003). M. P. Jesús María Lemos Bustamante.

Consejo de Estado, Sala Plena de lo Contencioso Administrativo. Sentencia exp. 76001233100020000251301 (27 de marzo de 2007). M. P. Jesús María Lemos Bustamante.

Consejo de Estado, Sección Segunda, Subsección B. Sentencia exp. 7300123310002001 0000601 (30 de julio de 2009). M. P. Víctor Hernando Alvarado Ardila.

Consejo de Estado, Sala de lo Contencioso Administrativo, Sección Tercera. Sentencia exp. 1900123310001998230001 , rad. int. 19957 (4 de mayo de 2011). M. P. Ruth Stella Correa.

Consejo de Estado. Sentencia exp. 1674-13 (20 de octubre de 2014). M. P. Alfonso Vargas Rincón.

Consejo de Estado. Sentencia exp. 4400-13 (19 de enero de 2015). M. P. Gustavo Eduardo Gómez Aranguren.

Consejo de Estado. Sentencia exp. 2013-00480 (16 de julio de 2015). M. P. Sandra Liseth Ibarra. 
Consejo de Estado. Sentencia exp. 3221-15 (1 de diciembre de 2016). M. P. William Hernández Gómez.

Consejo de Estado. Sentencia exp. 0842-2016 (22 de marzo de 2018). M. P. William Hernández Gómez.

Consejo Superior de la Judicatura, Sala Jurisdiccional Disciplinaria. Exp. 1100101020 0020110119800, rad. int. 1620 C (1 de junio de 2011). M. P. José Ovidio Claros Polanco.

Consejo Superior de la Judicatura, Sala Jurisdiccional Disciplinaria. Exp. 2013-01078 (5 de agosto de 2013). M. P. Pedro Alonso Sanabria.

Consejo Superior de la Judicatura, Sala Jurisdiccional Disciplinaria. Exp. 11001010200020130298200 (3 de diciembre de 2014). M. P. María Mercedes López.

Consejo Superior de la Judicatura, Sala Jurisdiccional Disciplinaria. Exp. 2016-00315 (20 de abril de 2016). M. P. Camilo Montoya Reyes.

Consejo Superior de la Judicatura, Sala Jurisdiccional Disciplinaria. Exp. 11001010200020160179800 (16 de febrero de 2017). M. P. José Ovidio Claros Polanco.

Corte Constitucional. Sentencia C-037 (5 de febrero de 1996). M. P. Vladimiro Naranjo Mesa.

Corte Constitucional. Sentencia C-400 (10 de agosto de 1998). M. P. Alejandro Martínez Caballero.

Corte Constitucional. Auto 278, C. J. 001 (9 de julio de 2015). M. P. Luis Guillermo Guerrero.

Corte Constitucional. Sentencia SU-406 (4 de agosto de 2016). M. P. Luis Guillermo Guerrero. 
Corte Constitucional. Sentencia SU-336 (18 de mayo de 2017). M. P. Iván Humberto Escrucería Mayolo.

Corte Constitucional. Sentencia T-198 (22 de mayo de 2018). M. P. Gloria Stella Ortiz Delgado.

CorteSuprema de Justicia, Sala de Casación Civil. Sentencia exp. 11001020300020050025101 (25 de junio de 2009). M. P. William Namen Vargas.

Couture, E. (1966). Fundamentos del derecho procesal civil. Buenos Aires: De Palma.

De Otto, I. (1995). Derecho constitucional. Sistema de fuentes. Madrid: Ariel.

Devis Echandía, H. (1961). Tratado de derecho procesal civil. Parte general. Tomo I. Bogotá: Temis.

García de Enterría, E. y Fernández, T.-R. (2006). Curso de Derecho Administrativo II. Madrid: Civitas/Thomson-Reuters.

Güechá Medina, C. N. (2016). Derecho procesal administrativo. Bogotá: Ibáñez.

Juzgado Primero Laboral del Circuito de Sogamoso. Auto exp. 2016-00238 (15 de junio de 2018). Juez Luis Robayo Pedraza.

Legis Editores (2012). Conciliación extrajudicial en asuntos de lo contencioso administrativo. Bogotá: Legis.

López Blanco, H. F. (2009). Instituciones de derecho procesal civil colombiano. Tomo I. Parte general. Bogotá: Dupre.

López Medina, D. (2006). El derecho de los jueces. Bogotá: Legis.

Marinoni, L. G. (2012). El precedente en la dimensión de la seguridad jurídica. Revista Ius et Praxis, 18(1), 249-266. DOI: https://doi.org/10.4067/s0718-00122012000100008 
VIeI Revista Virtual

Via Inveniendi et Iudicandi

Moral Soriano, L. (2002). El precedente judicial. Madrid: Marcial Pons.

Parra, M. (2004). El precedente judicial en el derecho comparado. Criterio Jurídico, 1(4), 239-262.

Santofimio Gamboa, J. O. (2004). Tratado de derecho administrativo. Bogotá: Universidad Externado de Colombia.

Tribunal Superior del Distrito Judicial de Bogotá, Sala Civil. Auto (11 de julio de 2005). M. P. Dora Consuelo Benítez.

Tribunal Superior del Distrito Judicial de Pereira, Sala Laboral. Auto exp. 66001310500420110048201 (27 de octubre de 2015). M. P. Julio César Salazar Muñoz. 